\title{
Relationship of Sleep to Pulmonary Function in Mucopolysaccharidosis II
}

\author{
William I. Wooten III, MD., \\ Department of Pediatrics, Division of Pulmonology, University of North Carolina at Chapel Hill. \\ Address: 450 MacNider Hall, Campus Box \#7217, Chapel Hill, NC 27599-7217. Phone: \\ 919-966-1055. Fax: 919-966-6179
}

Joseph Muenzer, MD., PhD, Department of Pediatrics, Division of Genetics and Metabolism, University of North Carolina at Chapel Hill

Bradley V. Vaughn, MD., and Department of Neurology, Division of Sleep Medicine, University of North Carolina at Chapel Hill

Marianne S. Muhlebach, MD.

Department of Pediatrics, Division of Pulmonology, University of North Carolina at Chapel Hill

William I. Wooten: wwooten@med.unc.edu

\begin{abstract}
Objective-To study the sleep characteristics, pulmonary function, and their relationships in an enzyme naive population of patients with mucopolysaccharidosis (MPS) II (Hunter syndrome).
\end{abstract}

Study design-The analyzed subjects (30 patients with MPS II with a median age of 9 years) had been enrolled in an MPS II natural history study and a phase I/II enzyme replacement clinical study in which they underwent standard polysomnography including spirometry and plethysmography, if cooperative. Descriptive statistics and nonparametric correlation were performed for demographic, sleep, and pulmonary function variables.

Results-Median apnea-hypopnea index (AHI) was 6.4, with obstructive sleep apnea (OSA) observed in 27/30 subjects. Sleep architecture was characterized by diminished rapid-eye movement (REM) sleep duration (median 13\%), and decline in sleep efficiency and slow-wave sleep (SWS) duration in older individuals. Oxygen desaturation below 90\% occurred in 26/30 subjects, and hypoventilation above 50 torr occurred in 11/23 subjects with accurate end-tidal carbon dioxide $\left(\mathrm{ETCO}_{2}\right)$ recordings. Of fifteen subjects with reliable spirometry, median forced expiratory volume in 1 second $\left(\mathrm{FEV}_{1}\right)$ was below $80 \%$ predicted in $12 / 15$ subjects. $\mathrm{FEV}_{1}$ in percent-predicted $\left(\mathrm{FEV}_{1} \%\right)$ was inversely related to $\mathrm{AHI}$ and increase from baseline $\mathrm{ETCO}_{2}$ $\left(\mathrm{p}=0.023, \mathrm{r}_{\mathrm{s}}=-0.58\right),\left(\mathrm{p}<0.001, \mathrm{r}_{\mathrm{s}}=-0.82\right)$.

Conclusion-Sleep in MPS II is characterized by OSA, altered sleep architecture, and impaired gas exchange. Sleep disruption is related to daytime pulmonary function, thus both systems should be evaluated when sleep abnormalities are suspected.

(C) 2012 Mosby, Inc. All rights reserved.

Correspondence to: William I. Wooten, III, wwooten@med. unc . edu.

The other authors declare no conflicts of interest.

Publisher's Disclaimer: This is a PDF file of an unedited manuscript that has been accepted for publication. As a service to our customers we are providing this early version of the manuscript. The manuscript will undergo copyediting, typesetting, and review of the resulting proof before it is published in its final citable form. Please note that during the production process errors may be discovered which could affect the content, and all legal disclaimers that apply to the journal pertain. 


\section{Keywords}

Hunter syndrome; MPS; apnea; polysomnography; obstructive sleep apnea; hypoventilation; pulmonary function; spirometry; plethysmography

The mucopolysaccharidoses (MPS) comprise a group of inherited disorders due to the specific deficiency of a lysosomal enzyme and are clinically characterized by multiple organ systems involvement and reduced life expectancy. Airway involvement and sleep problems are common in most types of MPS, often involving altered sleep regulation and obstructive sleep apnea (OSA) [1-5]. Early identification and treatment of sleep disorders is recommended to prevent worsening of neurocognitive and cardiovascular function [6-8].

Mucopolysaccharidosis (MPS) II (Hunter syndrome), an X-linked recessive disorder, is caused by the deficiency of iduronate sulfatase and presents with a wide spectrum of clinical severity. The severe form of MPS II is characterized by mental retardation, communicating hydrocephalus, hearing impairment, coarse facial features, hepatomegaly, obstructive airway disease, cardiac dysfunction, joint stiffness, skeletal involvement and premature death. The attenuated form of MPS II has similar albeit milder progression of somatic involvement without the cognitive impairment, and these patients usually live into adulthood [7].

Although sleep is usually disrupted in MPS II, there are few studies describing sleep characteristics in an enzyme naive population. Existing studies are limited by small sample sizes, lack of standardized polysomnography and inclusion of other MPS types [1, 2, 9-11]. The natural history of sleep disorders in MPS II has not been described, which is an essential prerequisite to evaluate the benefits of enzyme replacement therapy (ERT) that has become standard of care. Airway obstruction is typical and often severe in MPS II, probably due mostly to glycosaminoglycan (GAG) deposits within soft tissues of the upper and lower respiratory tract. Restrictive lung disease, related to abnormal body shape, kyphoscoliosis and altered chest wall dynamics, is also common. Thus the combination of restrictive and obstructive disease may contribute to respiratory insufficiency, which further affects hypoventilation during sleep $[12,13]$.

The aim of this cross-sectional study was to characterize baseline sleep patterns in patients with MPS II naive to enzyme therapy, and to correlate the sleep disturbance with pulmonary disease.

\section{METHODS}

We identified 30 patients with MPS II enrolled in research studies at the University of North Carolina at Chapel Hill (UNC-CH) who underwent polysomnography and pulmonary function testing. Two additional patients with tracheostomies were excluded. Diagnosis of MPS II was based on deficient iduronate sulfatase activity in serum, plasma or leukocytes and another normal sulfatase. Ten attenuated subjects were part of a phase I/II ERT clinical trial of iduronidase with data from April to October 2001 [9]. The remaining 20 subjects were studied as part of a natural history study sponsored by Transkaryotic Therapies, Inc. with the initial clinical evaluation from November 2002 to March 2003. No subject had received ERT at the time of clinical testing. The UNC-CH institutional review board approved the original studies, and permission was granted by the UNC-CH institutional review board to review this information without need to reconsent the subjects.

Demographic data and clinical history were obtained from the research and clinical records, including age, height, weight, ethnicity, comorbid medical conditions, medications, use of continuous positive airway pressure (CPAP), and previous airway surgery. Growth and body 
mass index (BMI) percentiles were calculated based on the United States Centers for Disease Control and Prevention (CDC) guidelines [14].

Standard overnight polysomnography was performed in the clinical sleep laboratory of UNC Hospitals, including nasal pressure and end-tidal carbon dioxide $\left(\mathrm{ETCO}_{2}\right)$ measurements. Subjects treated chronically with CPAP underwent split-night studies, and the portion of the study using CPAP was excluded from analysis. Studies were interpreted by a certified sleep physician using standard criteria consistent with the 2007 American Academy of Sleep Medicine (AASM) scoring guidelines for pediatrics [15].

Spirometry was performed in accordance with American Thoracic Society standards, typically within a few days of polysomnography [16]. Values of percent-predicted for spirometry were expressed using reference values based on age, height and race according to Hankinson, et al [17]. For three children less than 7 years of age able to perform spirometry, percentiles were calculated per standard preschool reference equations published by Eigen, et al [18]. Lung volumes were measured using body plethysmography and percentiles calculated using standard reference equations [19].

\section{Statistical analyses}

Descriptive statistics were calculated for demographics, polysomnography, and pulmonary function results. Because of small sample size and variability of results, data are reported using median and range with nonparametric analyses. Two-tailed Spearman rank correlation was performed to identify significant relationships between subject characteristics, sleep and respiratory variables. Analysis was completed using GraphPad Prism version 5.0.

\section{RESULTS}

Subject demographic and clinical characteristics are summarized in Table I. All thirty subjects were male, and all but three were Caucasian. In order to cooperate with required testing, patients in the Phase I/II ERT clinical trial group were older and included only those with the attenuated phenotype. In the entire population, airway surgery had been performed in ten subjects. All of these surgeries had been performed more than two years prior to our study, and the majority had been performed at other centers. Of those who did not have airway surgery, 6 of 20 had history of other surgeries, including hernia repair, spinal fusion, VP shunt placement, and repair of Arnold-Chiari malformation.

Significant comorbidities reported by subjects included asthma (4), gastroesophageal reflux disease (2), aspiration (2), prematurity (2), and immunodeficiency (1). Daily use of medications was reported by 22 of 30 subjects. Three subjects reported regular use of medications for sleep, including zolpidem, melatonin and chloral hydrate. Other medications, in order of frequency, included inhaled beta-agonists (10), non-steroidal antiinflammatory drugs (9), antihistamines (5), inhaled corticosteroids (4), over-the counter cold remedies (3), angiotensin-converting enzyme inhibitor or angiotensin-receptor blocker (3), leukotriene modifier (3), proton pump inhibitor (3), antibiotics (3), nasal corticosteroids (2), cromolyn (1), beta blocker (1), $\mathrm{H}_{2}$ blocker (1), carbamazepine (1), and baclofen (1).

\section{Sleep parameters}

Descriptive statistics for sleep parameters are presented in Table II. Sleep efficiency was inversely related to age (Figure 1, B). Sleep was characterized by a variable number of arousals, with more than 12 arousals per hour in 6/30 subjects. As REM sleep occurs predominantly during the second half of the night and thus might affect comparison in patients undergoing the split-night protocol with CPAP, we omitted four subjects on CPAP for comparison of REM sleep. In the remaining 26 subjects, REM sleep duration was 
reduced compared with age expected norms, with a median of $11 \%(0.7-23 \%)$ in subjects less than 10 years of age and 16\% (11-24\%) in subjects over age 10 [20]. Percentage of slow-wave sleep (SWS) and stage I sleep were related to subject age (Figure 1, C and D).

The overall median AHI was 6.4 events per hour, with OSA identified in 27/30 subjects based on AHI greater than 1.5. Moderate to severe OSA was present in 18/30 and eleven subjects were severely affected with AHI greater than 10. Overall REM AHI was higher than non-REM AHI, and 19 subjects had REM-related OSA based on REM AHI > 10. Of the six patients with prior adenotonsillectomy as therapy for OSA, five had persistent OSA, three with AHI greater than 10. Severity of OSA was not related to age (Table II) but was directly related to $\mathrm{BMI}\left(\mathrm{p}=0.038, \mathrm{r}_{\mathrm{s}}=0.38\right)$.

\section{Gas exchange abnormalities}

The median minimum peripheral oxygen saturation $\left(\mathrm{SpO}_{2}\right)$ was $81 \%$, and decreased below $90 \%$ in 26/30 individuals. The median desaturation index (number of $23 \%$ desaturation events per hour) was 6.4. Minimum $\mathrm{SpO}_{2}$ and desaturation index were correlated to AHI $\left(\mathrm{p}=0.006, \mathrm{r}_{\mathrm{s}}=-0.49\right),\left(\mathrm{p}=0.002, \mathrm{r}_{\mathrm{s}}=0.54\right)$. Serum bicarbonate while awake was normal in all subjects, however $\mathrm{ETCO}_{2}$ increased above 50 torr in 11/23 subjects with accurate measurements. Maximum $\mathrm{ETCO}_{2}$ was directly related to age (Table II and Figure 1, E) and BMI ( $\left.\mathrm{p}=0.017, \mathrm{r}_{\mathrm{s}}=0.49\right)$. The difference between maximum and initial $\mathrm{ETCO}_{2}$ was related to AHI $\left(\mathrm{p}=0.004, \mathrm{r}_{\mathrm{s}}=0.58\right)$.

\section{Pulmonary function tests}

Fifteen subjects were able to reproducibly perform spirometry, excluding two individuals with a tracheostomy (Table II). Forced vital capacity (FVC) was less than $80 \%$ predicted in $11 / 15$. Forced expiratory volume in 1 second $\left(\mathrm{FEV}_{1}\right)$ was less than $80 \%$ predicted in $12 / 15$, with $10 / 15$ below $65 \%$ predicted. $\mathrm{FEV}_{1} / \mathrm{FVC}$ was less than 0.8 in $7 / 15$ subjects, indicating obstructive pulmonary impairment. FVC and $\mathrm{FEV}_{1}$ in percent-predicted (FVC \%, $\mathrm{FEV}_{1} \%$ ) did not correlate with age but did correlate with BMI ( $\mathrm{p}=0.007, \mathrm{r}_{\mathrm{s}}=-0.66$ for both).

Six of the 14 individuals who successfully performed plethysmography demonstrated reduction in total lung capacity (TLC) below $80 \%$ predicted. Ratio of residual volume to total lung capacity (RV/TLC) was 0.4 or greater in 11 of 14 subjects. RV/TLC was directly related to age (Figure 1, F).

\section{Relationships of polysomnography to pulmonary function}

$\mathrm{FEV}_{1} \%$ and RV/TLC were correlated to AHI ( $\left.\mathrm{p}=0.023, \mathrm{r}_{\mathrm{s}}=-0.58\right),\left(\mathrm{p}=0.019, \mathrm{r}_{\mathrm{s}}=0.62\right)$ and minimum SpO2 $\left(\mathrm{p}=0.011, \mathrm{r}_{\mathrm{s}}=0.63\right),\left(\mathrm{p}=0.002, \mathrm{r}_{\mathrm{s}}=-0.75\right)$. The six patients with RV/TLC over 0.5 all had minimum $\mathrm{SpO}_{2}$ of $75 \%$ or lower. Degree of sleep related hypoventilation, as measured by change from baseline $\mathrm{ETCO}_{2}$, was correlated with $\mathrm{FEV}_{1} \%$ and RV/TLC (Figure 2).

\section{DISCUSSION}

We observed that abnormal architecture, OSA, and gas exchange abnormalities characterize sleep in patients with MPS II. Most individuals also had significant pulmonary impairment, mostly a combination of obstructive and restrictive lung disease. Our results suggest that pulmonary function may predict extent of OSA and hypoventilation, which has not previously been described in MPS.

Sleep architecture in MPS II appears to be characterized by diminished REM sleep, along with higher rates of decline in efficiency and SWS in older individuals than observed in the 
general population [20]. Although the etiology of the reduced duration of REM sleep in patients with the severe phenotype of MPS II is unclear, this might reflect neurological changes in REM sleep control mechanisms in the brainstem and diencephalon. Most likely, alterations in sleep state control are largely secondary to OSA and associated poor sleep quality. OSA was nearly universal in this population, often severe and persistent despite prior surgical interventions.

Propensity for OSA is the consequence of numerous disease-related factors, including deposits within the upper airway, glossoptosis, adenotonsillar hypertrophy, and impaired respiratory control. Such high prevalence of OSA bears important clinical consequences in this population because of its negative effects on neurocognitive function and cardiovascular morbidity [6]. Further, despite the severity of OSA, patients exhibited relatively normal arousal indices for age, possibly increasing risk for morbidity and mortality during sleep [21].

Body habitus, GAG deposits in upper airway, and altered chest wall dynamics in MPS II likely compound the sleep related problems. Similar to the general population, individuals with the highest BMI were noted to have more severe OSA [22]. Diminished height, scoliosis, and excess soft tissue adjacent to the lungs and airway may increase propensity for airway collapse, especially during sleep, a time of relative airway hypotonia. As airway tone is lowest during REM sleep, the high prevalence of REM-related OSA supports this notion. Therefore, in spite of their abnormal growth, controlling BMI by limiting weight gain should be attempted in patients with MPS II to improve their pulmonary function.

Impaired oxygenation and ventilation during sleep, observed in the majority of individuals with MPS II, may be a consequence of poor ventilatory reserve in the context of restrictive pulmonary disease and OSA. Blunted central ventilatory responsiveness is another consideration, possibly related to body structure as observed in obesity-hypoventilation syndrome versus a representation of neurologic involvement in MPS [23]. All our subjects had normal awake serum $\mathrm{CO}_{2}$, suggesting that pulmonary disease was not sufficiently severe to cause persistent hypercarbia. Sleep-related hypoventilation corresponded to daytime pulmonary function, which suggests that pulmonary function tests could serve as an important clinical predictor of the presence of these gas-exchange abnormalities.

As in other syndromes with short stature, accurate interpretation of lung function poses challenges because parameters in children are typically expressed in percent-predicted based on height for a given age. Absolute values of $\mathrm{FVC}$ and $\mathrm{FEV}_{1}$ showed minimal change with age, which coincides with lack of physical and chest growth in these subjects. Measures that are independent of height $\left(\mathrm{FEV}_{1} / \mathrm{FVC}\right.$ and $\left.\mathrm{RV} / \mathrm{TLC}\right)$ were often abnormal, the latter correlating with age consistent with disease progression. RV/TLC is a sensitive measure of lower airway obstruction and air-trapping, whereas $\mathrm{FEV}_{1} / \mathrm{FVC}$ is more indicative of larger airway obstruction. Such obstructive disease in MPS can result from GAG deposits in the lower airway, chronic inflammation, or infection. At our center, patients with MPS often undergo flexible bronchoscopy at the time of surgical interventions which allows assessment of the upper and lower airway for GAG deposits. Review of these bronchoscopies has revealed a high prevalence of widespread deposits, frequently involving the lower airway [24]. Future studies might employ direct visualization or imaging of the lower airway along with polysomnography to better characterize these processes.

The relationship of pulmonary function and sleep-related gas exchange may be important clinically. As observed in our population, pulmonary function testing is difficult to obtain in many patients with MPS due to neurologic involvement. In these patients, overnight polysomnography with capnography may be helpful to gauge the degree of pulmonary 
impairment. Conversely, for those patients who are able to perform pulmonary function reliably, this information may be useful to predict the likelihood of OSA and hypoventilation. Plethysmography may be beneficial to determine total lung capacity for suggestion of restrictive disease and RV/TLC, which appears closely related to sleep-related gas exchange abnormalities.

Systemic ERT is expected to improve somatic manifestations of contractures, restrictive lung disease and upper airway GAG deposits, but neurologic improvement is not expected because idursulfase is unable to traverse the blood-brain barrier [25]. The phase II/III clinical trials of idursulfase showed improvement in lung function and subsequent smaller studies seemed to indicate improved sleep parameters [26, 27]. Further studies are needed to more fully understand how ERT may affect sleep among other factors in MPS. Our findings in an ERT naive population provide important baseline characteristics of sleep and lung function for comparing patients with MPS II who now receive ERT.

We acknowledge limitations to our study, including that we did not examine patients longitudinally but rather assessed a cross-sectional cohort. As many aspects of disease worsen with age, it remains impossible to define contribution of individual factors to sleep parameters. The relatively small sample size, which is inherent to study of a rare disease, does not allow subgroup analyses of surgeries and medications. Similarly we cannot exclude a survivor and floor effect in this cross-sectional group where sicker patients have not survived to be studied at advanced ages.

According to guidelines by the American Academy of Sleep Medicine, there was not enough evidence to routinely recommend polysomnography in children with chronic respiratory diseases, including asthma, cystic fibrosis, and neuromuscular disorders [28]. Subsequently, clinical screening is needed to determine need for polysomnography. In cystic fibrosis, a progressive childhood disease with primarily obstructive lung disease, a similar relationship between lung function and sleep-related hypoventilation has been suggested [29]. As observed in our MPS II population, pulmonary function testing may provide a useful screening tool to predict the presence of obstructive apnea and gas-exchange abnormalities.

\section{Acknowledgments}

J. M. was the principal investigator for both the MPS II phase I/II enzyme replacement clinical trial and the MPS II natural history studies at UNC, and has served as a consultant to Shire Human Genetic Therapies, Inc (Cambridge, MA) for the development of enzyme replacement therapy for the treatment of MPS II. B.V. has received funding from Glaxo Smith Kline and Johns Hopkins University for research in Restless Legs Syndrome.

\section{Abbreviations}

$\begin{array}{ll}\text { MPS } & \text { Mucopolysaccharidosis } \\ \text { GAG } & \text { Glycosaminoglycan } \\ \text { AHI } & \text { Apnea-hypopnea index } \\ \text { OSA } & \text { Obstructive sleep apnea } \\ \text { REM } & \text { Rapid eye movement } \\ \text { SWS } & \text { Slow-wave sleep } \\ \text { ETCO }_{2} & \text { End-tidal carbon dioxide } \\ \text { SpO }_{2} & \text { Oxygen saturation per pulse oximetry }\end{array}$




$\begin{array}{ll}\text { FEV } 1 & \text { Forced expiratory volume in } 1 \text { second } \\ \text { FEV }_{1} \% & \text { Forced expiratory volume in } 1 \text { second }- \text { percent predicted } \\ \text { FVC } & \text { Forced vital capacity } \\ \text { FVC \% } & \text { Forced vital capacity - percent predicted } \\ \text { TLC } & \text { Total lung capacity } \\ \text { RV/TLC } & \text { Ratio of residual volume to total lung capacity } \\ \text { CPAP } & \text { Continuous positive airway pressure } \\ \text { BMI } & \text { Body mass index } \\ \text { ERT } & \text { Enzyme replacement therapy }\end{array}$

\section{References}

1. Lin HY, Chen MR, Lin CC, Chen CP, Lin DS, Chuang CK, et al. Polysomnographic characteristics in patients with mucopolysaccharidoses. Pediatric pulmonology. 2010; 45:1205-12. [PubMed: 20717914]

2. Leighton SE, Papsin B, Vellodi A, Dinwiddie R, Lane R. Disordered breathing during sleep in patients with mucopolysaccharidoses. International journal of pediatric otorhinolaryngology. 2001; 58:127-38. [PubMed: 11278021]

3. Fraser J, Wraith JE, Delatycki MB. Sleep disturbance in mucopolysaccharidosis type III (Sanfilippo syndrome): a survey of managing clinicians. Clinical genetics. 2002; 62:418-21. [PubMed: 12431260]

4. Guerrero JM, Pozo D, Diaz-Rodriguez JL, Martinez-Cruz F, Vela-Campos F. Impairment of the melatonin rhythm in children with Sanfilippo syndrome. Journal of pineal research. 2006; 40:192-3. [PubMed: 16441557]

5. John A, Fagondes S, Schwartz I, Azevedo AC, Barrios P, Dalcin P, et al. Sleep abnormalities in untreated patients with mucopolysaccharidosis type VI. American journal of medical genetics Part A. 2011; 155A:1546-51. [PubMed: 21638759]

6. Capdevila OS, Kheirandish-Gozal L, Dayyat E, Gozal D. Pediatric obstructive sleep apnea: complications, management, and long-term outcomes. Proceedings of the American Thoracic Society. 2008; 5:274-82. [PubMed: 18250221]

7. Muenzer J, Beck M, Eng CM, Escolar ML, Giugliani R, Guffon NH, et al. Multidisciplinary management of Hunter syndrome. Pediatrics. 2009; 124:e1228-39. [PubMed: 19901005]

8. Martins AM, Dualibi AP, Norato D, Takata ET, Santos ES, Valadares ER, et al. Guidelines for the management of mucopolysaccharidosis type I. The Journal of pediatrics. 2009; 155:S32-46. [PubMed: 19765409]

9. Muenzer J, Gucsavas-Calikoglu M, McCandless SE, Schuetz TJ, Kimura A. A phase I/II clinical trial of enzyme replacement therapy in mucopolysaccharidosis II (Hunter syndrome). Molecular genetics and metabolism. 2007; 90:329-37. [PubMed: 17185020]

10. Santamaria F, Andreucci MV, Parenti G, Polverino M, Viggiano D, Montella S, et al. Upper airway obstructive disease in mucopolysaccharidoses: polysomnography, computed tomography and nasal endoscopy findings. Journal of inherited metabolic disease. 2007; 30:743-9. [PubMed: 17570075]

11. Nashed A, Al-Saleh S, Gibbons J, MacLusky I, MacFarlane J, Riekstins A, et al. Sleep-related breathing in children with mucopolysaccharidosis. Journal of inherited metabolic disease. 2009; 32:544-50. [PubMed: 19562504]

12. Muhlebach MS, Wooten W, Muenzer J. Respiratory manifestations in mucopolysaccharidoses. Paediatric respiratory reviews. 2011; 12:133-8. [PubMed: 21458742]

13. Chebbo A, Tfaili A, Jones SF. Hypoventilation syndromes. The Medical clinics of North America. 2011; 95:1189-202. [PubMed: 22032434] 
14. Kuczmarski RJ, Ogden CL, Grummer-Strawn LM, Flegal KM, Guo SS, Wei R, et al. CDC growth charts: United States. Adv Data. 2000:1-27. [PubMed: 11183293]

15. Iber, C. American Academy of Sleep Medicine. The AASM manual for the scoring of sleep and associated events: rules, terminology and technical specifications. Westchester, IL: American Academy of Sleep Medicine; 2007.

16. American Thoracic Society. Standardization of Spirometry, 1994 Update. American journal of respiratory and critical care medicine. 1995; 152:1107-36. [PubMed: 7663792]

17. Hankinson JL, Odencrantz JR, Fedan KB. Spirometric reference values from a sample of the general U.S. population. American journal of respiratory and critical care medicine. 1999; 159:179-87. [PubMed: 9872837]

18. Eigen H, Bieler H, Grant D, Christoph K, Terrill D, Heilman DK, et al. Spirometric pulmonary function in healthy preschool children. American journal of respiratory and critical care medicine. 2001; 163:619-23. [PubMed: 11254514]

19. Quanjer PH, Tammeling GJ, Cotes JE, Pedersen OF, Peslin R, Yernault JC. Lung volumes and forced ventilatory flows. Report Working Party Standardization of Lung Function Tests, European Community for Steel and Coal. Official Statement of the European Respiratory Society. The European respiratory journal Supplement. 1993; 16:5-40. [PubMed: 8499054]

20. Ohayon MM, Carskadon MA, Guilleminault C, Vitiello MV. Meta-analysis of quantitative sleep parameters from childhood to old age in healthy individuals: developing normative sleep values across the human lifespan. Sleep. 2004; 27:1255-73. [PubMed: 15586779]

21. Scholle S, Wiater A, Scholle HC. Normative values of polysomnographic parameters in childhood and adolescence: arousal events. Sleep medicine. 2012; 13:243-51. [PubMed: 22261241]

22. Kohler MJ, Thormaehlen S, Kennedy JD, Pamula Y, van den Heuvel CJ, Lushington K, et al. Differences in the association between obesity and obstructive sleep apnea among children and adolescents. Journal of clinical sleep medicine: JCSM: official publication of the American Academy of Sleep Medicine. 2009; 5:506-11. [PubMed: 20465015]

23. Mokhlesi B, Tulaimat A. Recent advances in obesity hypoventilation syndrome. Chest. 2007; 132:1322-36. [PubMed: 17934118]

24. Muhlebach MS, Shaffer C, Georges L, Abode K, Muenzer J. Bronchoscopy and airway management in patients with mucopolysaccharidoses (MPS). Pediatric pulmonology. 2012 Accepted, in print.

25. Muenzer J, Bodamer O, Burton B, Clarke L, Frenking GS, Giugliani R, et al. The role of enzyme replacement therapy in severe Hunter syndrome-an expert panel consensus. European journal of pediatrics. 2012; 171:181-8. [PubMed: 22037758]

26. Muenzer J, Wraith JE, Beck M, Giugliani R, Harmatz P, Eng CM, et al. A phase II/III clinical study of enzyme replacement therapy with idursulfase in mucopolysaccharidosis II (Hunter syndrome). Genet Med. 2006; 8:465-73. [PubMed: 16912578]

27. Okuyama T, Tanaka A, Suzuki Y, Ida H, Tanaka T, Cox GF, et al. Japan Elaprase Treatment (JET) study: idursulfase enzyme replacement therapy in adult patients with attenuated Hunter syndrome (Mucopolysaccharidosis II, MPS II). Molecular genetics and metabolism. 2010; 99:18-25. [PubMed: 19773189]

28. Wise MS, Nichols CD, Grigg-Damberger MM, Marcus CL, Witmans MB, Kirk VG, et al. Executive summary of respiratory indications for polysomnography in children: an evidence-based review. Sleep. 2011; 34:389-98AW. [PubMed: 21359088]

29. Bradley S, Solin P, Wilson J, Johns D, Walters EH, Naughton MT. Hypoxemia and hypercapnia during exercise and sleep in patients with cystic fibrosis. Chest. 1999; 116:647-54. [PubMed: 10492266] 
A

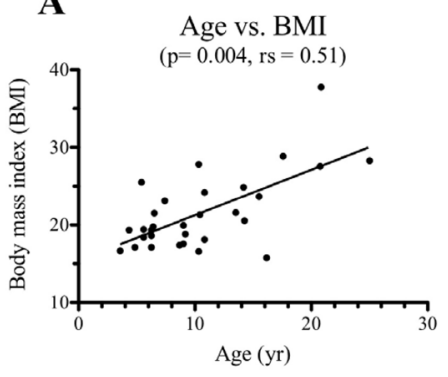

C

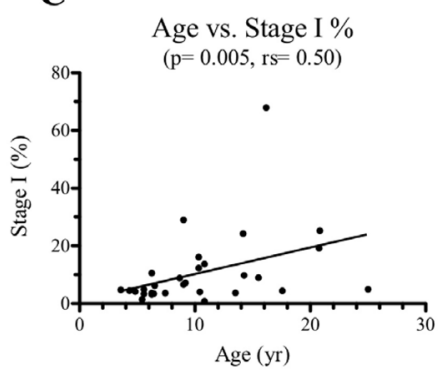

E

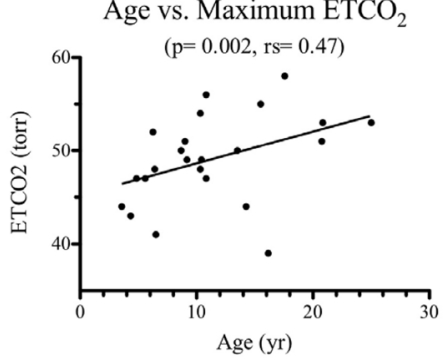

$\mathbf{B}$

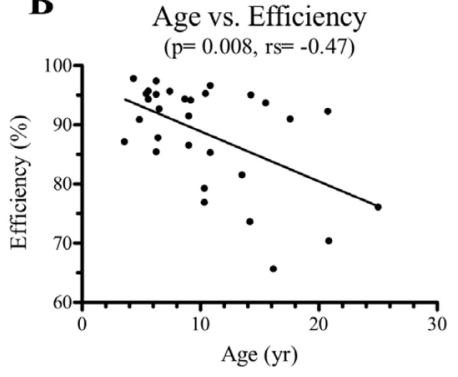

D

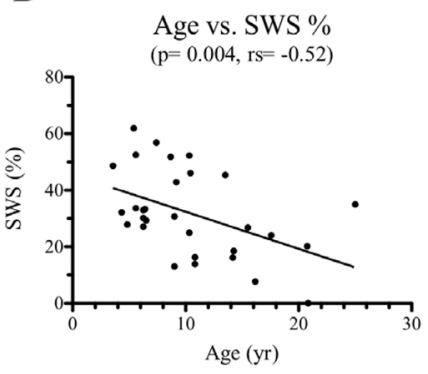

F

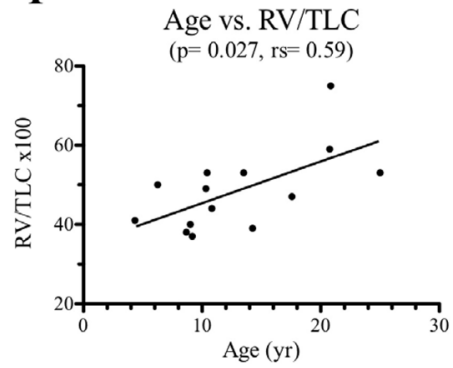

Figure 1.

Relationships of age to demographic and clinical characteristics. Age to: A, BMI, B, sleep efficiency, C, stage I sleep as percentage of total sleep time, D, SWS as percentage of total sleep time, E, maximum $\mathrm{ETCO}_{2}$, and F, RV/TLC. 
A

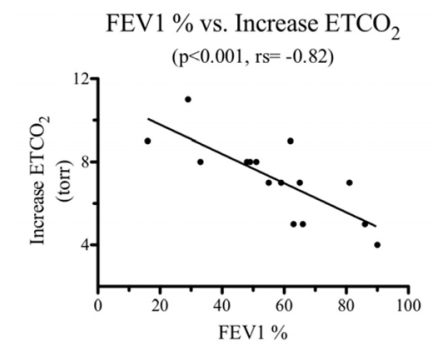

B

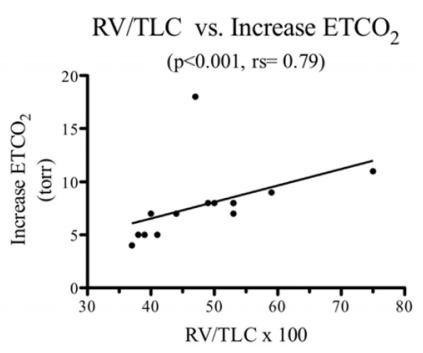

Figure 2.

Relationships of sleep-related hypoventilation as measured by increase from baseline $\mathrm{ETCO}_{2}$ to measures of pulmonary function. A. Increase in $\mathrm{ETCO}_{2}$ to $\mathrm{FEV}_{1} \%$. B, Increase in $\mathrm{ETCO}_{2}$ to $\mathrm{RV} / \mathrm{TLC}$. 


\section{Table I}

Subject demographic and clinical characteristics, grouped by study population

\begin{tabular}{|c|c|c|c|}
\hline & ERT trial $(n=10)$ & Natural history $(n=20)$ & Total $(n=30)$ \\
\hline Phenotype (attenuated / severe) & $10 / 0$ & $8 / 12$ & $18 / 12$ \\
\hline Age in years, median (range) & $12(6-21)$ & $8(3-25)$ & $9(3-25)$ \\
\hline Height percentile ${ }^{*}$ & $<3 \%$ & $<3 \%$ & $<3 \%$ \\
\hline Weight percentile ${ }^{*}$ & $35 \%$ & $60 \%$ & $52 \%$ \\
\hline BMI percentile* & $89 \%$ & $94 \%$ & $92 \%$ \\
\hline Prior $\mathrm{PSG}^{\dagger}$ & 2 & 1 & 3 \\
\hline Positive airway pressure during sleep & 3 & 1 & 4 \\
\hline Sleep medications & 0 & 3 & 3 \\
\hline Prior adenotonsillectomy & 5 & 1 & 6 \\
\hline Prior adenoidectomy alone & 1 & 1 & 2 \\
\hline Other airway surgery ${ }^{\dagger t}$ & 2 & 0 & 2 \\
\hline
\end{tabular}




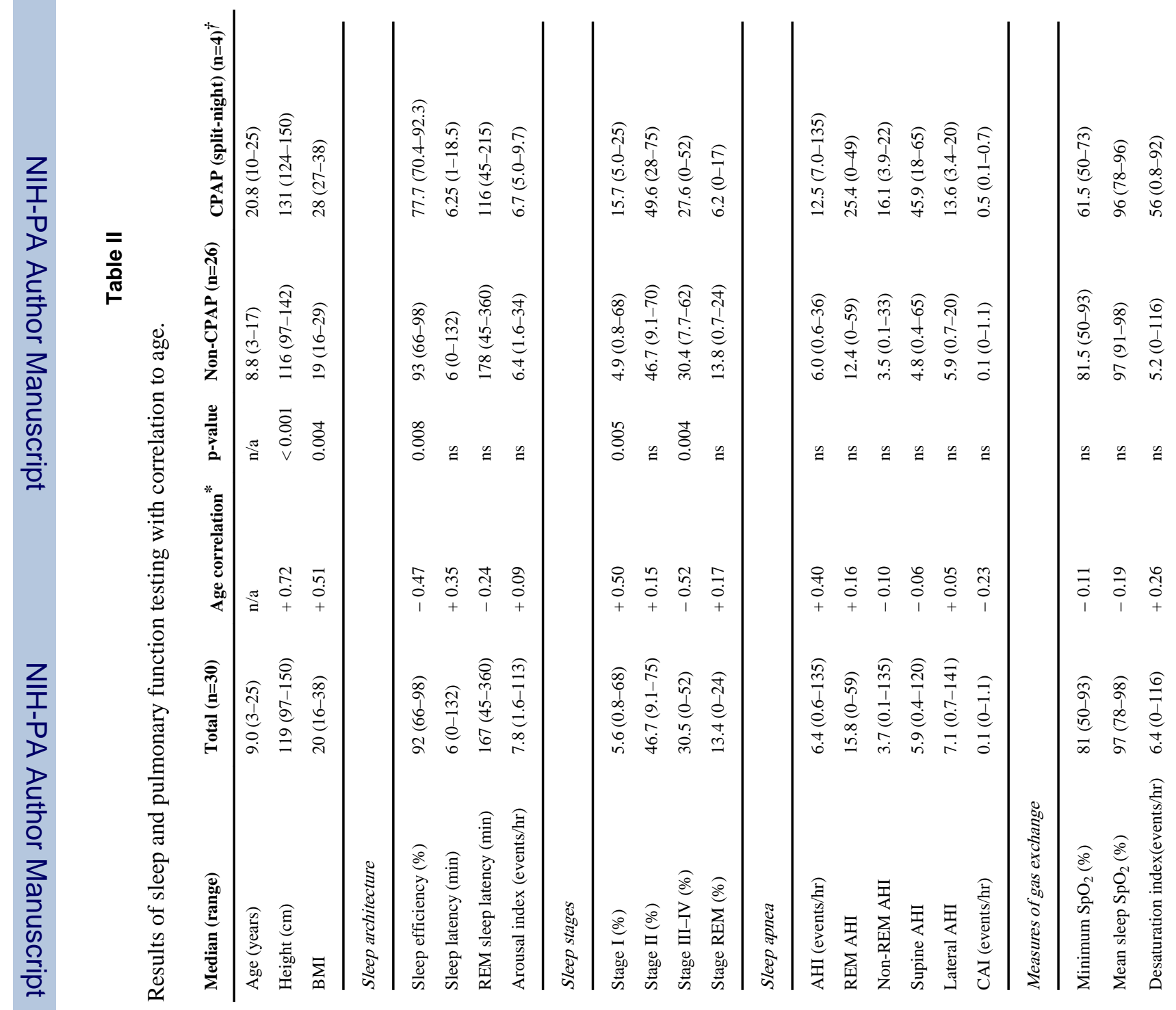


Wooten et al.

Page 13

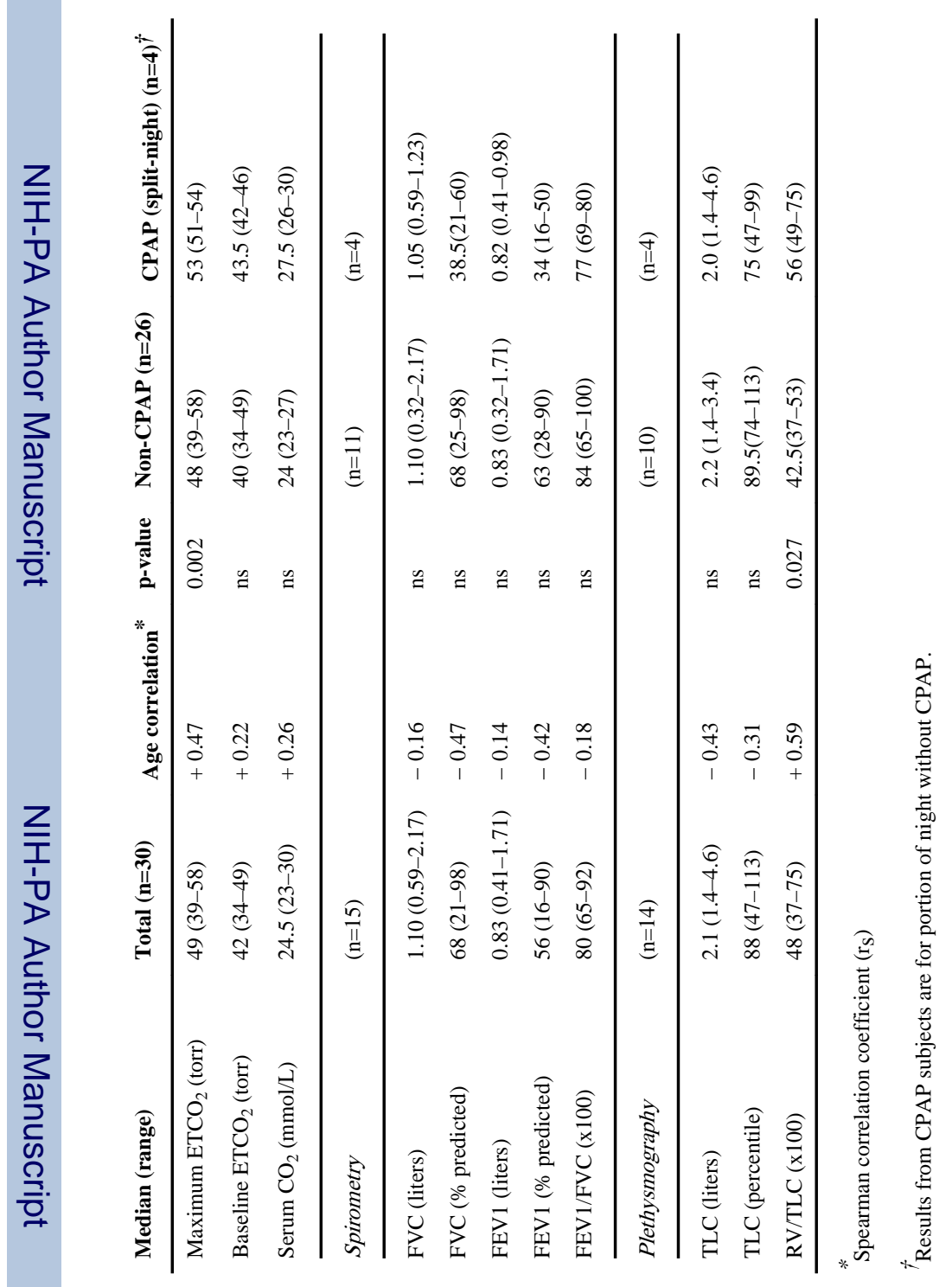

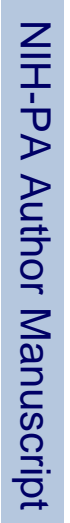

